
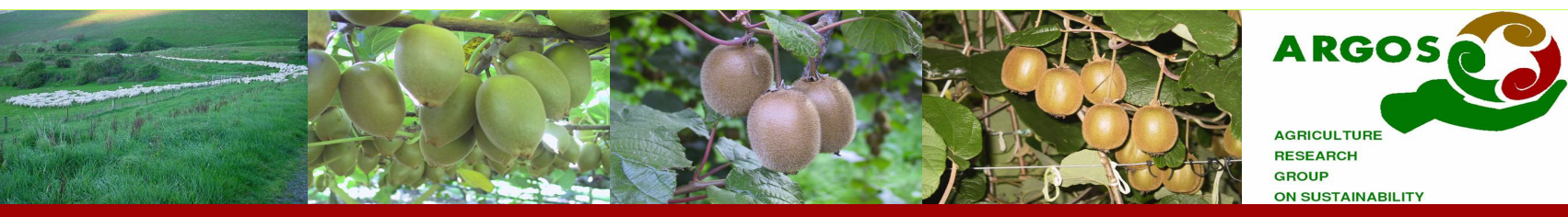

\title{
Diversity and abundance of birds in New Zealand kiwifruit orchards
}

Rate, S. ${ }^{1}$, Hunt, L. ${ }^{2}$, Rosin, C. ${ }^{1}$, Blackwell, G. ${ }_{1}^{1}$, and Moller, $H .{ }^{1}$

${ }^{1}$ The Agriculture Research Group on Sustainability, The University of Otago, PO Box 56, Dunedin, New Zealand.

${ }^{2}$ The Agriculture Research Group on Sustainability, Agribusiness and Economics Research Unit, PO Box 84, Lincoln University, New Zealand.

Corresponding author:

\section{Introduction}

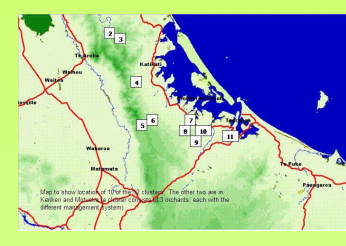

Figure 1: Orchard locations in this study

Both introduced and native bird species play important ecological and social roles in production landscapes. Economic benefits stem from birds that control pasture and crop pests, and many farmers and growers appreciate native species such as tui (Prosthemadera novaeseelandiae), wood pigeons (Hemiphaga novaeseelandiae), and fantails (Rhipidura fuliginosa) in farmland. Overseas food market chains and their customers are increasingly wishing to be assured that the food and fibre they buy from New Zealand farms has been produced in an ecologically sustainable way that supports other plants and animals in the farm landscape as well as the 'agricultural biodiversity' that directly assists production.

In New Zealand there is currently very little information available on the ecology or social roles of bird communities in production landscapes. This study forms part of a larger project, the Agriculture Research Group on Sustainability (ARGOS), which is investigating the social, economic and ecological sustainability of New Zealand Production landscapes. The specific research questions of this part of the project were:

- What impacts do alternative orchard productions systems have on bird communities?

- What knowledge do growers have of bird communities on their orchards and how does this compare with information from formal scientific surveys?

\section{Methods}

This study was conducted on 36 New Zealand kiwifruit orchards located in the Bay of Plenty ( $n=30$ orchards) and Bay of Islands $(N=3)$ in the North Island, and Motueka $(n=3)$ in the South Island. The orchards were arranged in clusters of three, matched for geology, climate and location. Each cluster contained a KiwiGreen Hayward (Green), KiwiGreen Hort 16A (Gold) and KiwiGreen Hayward Organic (Organic) orchard. In summer 2004/2005, bird community surveys were conducted on all orchards. A team of four observers recorded all birds seen or heard in a 5 minute period at between 3-15 randomly chosen points on each orchard. Comparisons were made between the bird communities present on Green, Gold and Organic orchards (termed farming systems in this study).

The frequency at which different species were recorded in the surveys was compared to grower awareness of birds on their orchards, as indicated by the numbers of growers that noted each species during sociological interviews.

\section{Results}

The most commonly recorded species in the orchards were non-native, including song thrush (Turdus philomelos), blackbird (T. merula) house sparrow (Passer domesticus), chaffinch (Fringilla coelebs) and Indian myna (Acridotheres tristis). However, some native species were commonly recorded on the orchards, including fantail ( $64 \%$ of orchards), kingfisher (Halcyon sancta: $58 \%$ of orchards) and silvereye (Zosterops lateralis : $31 \%$ of orchards).

Log total bird count was significantly higher on organic orchards than on either Green or Gold orchards $\left(F_{2.33}=8.61, p<0.001 ; r^{2}=38.25 \%\right.$, Figure 2 Top $)$. Log species richness was not significantly different between farming systems, although it was highest on organic orchards (Figure 2 Middle). The logtransformed proportion of species that were native was significantly different between the three farming systems types $\left(F_{233}=8.70, p<0.001 ; r^{2}=40.54 \%\right.$, Figure 2 Bottom)

There was a significant positive relationship between the proportion of orchards that birds were recorded on during the surveys and the numbers of times growers mentioned the same species in the interviews $\left(F_{139}=25.36, p<0.001: r^{2}=39.41\right.$ Figure 3).

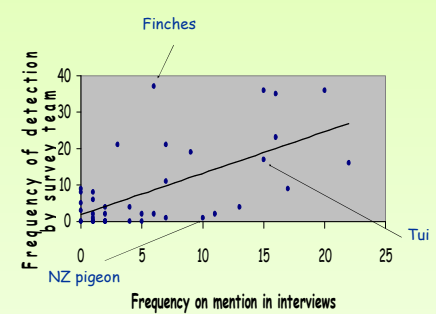

Figure 3: The number of growers that mentioned a particular species during social interviews $(X$ axis $)$ compared to the number of orchards on which that species was the two variables that explained $39 \%$ of the variation. Some highly visible native species
serifition rare native species were commented on by growers in much greater proportions than they were recorded in the field surveys (e.g. N.Z. pigeon). Conversely, the number of species of potential ecological or economic importance (e.g. chaffinch, greentinch and
goldfinch) were not individually recognized by growers and werf goldfinch) were not individual
together by them as finches.
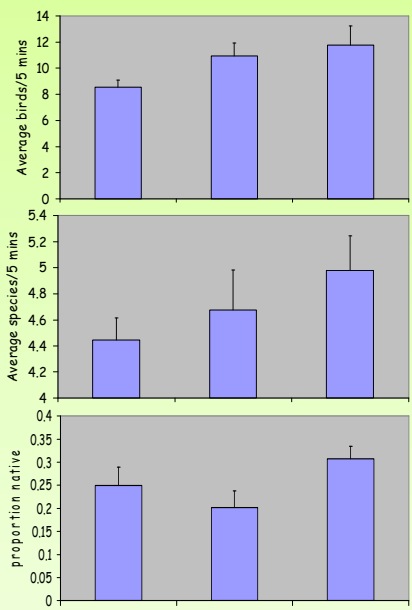

Organic

Farming systen

Figure 2: Comparison of bird communities on ARGOS KiwiGree Hort 16A (Gold), KiwiGreen Hayward (Green) and Hayward 1 minutes, Middle- Average number of species recorded in 5 minute sarveys, and Bottom- the average proportion of species recorded transtormed for analysis.

\section{Conclusions}

A number of valued native insectivorous (fantail and silvereye), nectivorous (tui) and frugivorous (kereru or wood pigeon) species occurred on the orchards. Growers had high awareness of the full range of species present on their orchards, and an acknowledged appreciation of native species.

There were differences in the bird communities found on Gold, Green and Organic orchards in the study, with significantly higher abundance and proportions of native species present on Organic orchards. These differences may be related in part to management of the habitat under the vines and at the ends of the rows in the different farming systems, with Organic orchards generally having longer and more diverse vegetation which may promote bird diversity. Other factors that may account for these differences are generally higher invertebrate biodiversity and biomass on Organic orchards (Steven et al. 2004; Pearson et al. 2005), active species encouragement by individual growers for aesthetic reasons (Hunt 2005), and issues of wider landscape diversity and complexity.

ARGOS kiwifruit growers have a detailed working knowledge of the birds present on their orchards, with recognition and awareness greatest for valued native species and real or perceived pest species. The comparison between grower responses and survey results illustrates one of the strengths of the ARGOS project, where growers deep qualitative knowledge of their environment is complimented by more focused quantitative information from the scientific surveys.

References

Steven, D. Benge, J. \& Moller. H. 2004. Spiders in kiwifruit orchards. ARGOS Research Note 5. The Agriculture Research Group on Sustainability.

Hunt, L., Rosin, C.., McLeod, C., Read, M., Fairweather, J., Campbell, H. 2005. Understanding Approaches to Kiwifruit Production in New Zealand: Report on First Qualitative Interviews of

Pearson, A., Reid, J. Benge, J., \& Moller, H. 2005. Soil quality on ARGOS kiwifruit orchards, 2004-2005. ARGOS Research Report 05/02. The Agriculture Research Group on Sustainability. 